\title{
Energy-efficient and cost-effective methods of driving trains under the conditions of development of the electricity market
}

\author{
Alexander Pshinko ${ }^{1}$, Andrii Afanasov ${ }^{1}$, Valeriy Kuznetsov ${ }^{2, *}$, Vladislav Skalozub ${ }^{1}$, Sergiy Arpul ${ }^{1}$, and Alexander Ivanov ${ }^{1}$ \\ ${ }^{1}$ DNURT, Dnipro, Ukraine \\ ${ }^{2}$ Railway Institute, Poland
}

\begin{abstract}
The article for the first time considers the possibilities for the organization of cost-effective rail transportation on electrified section in terms of the functioning of the Ukrainian balancing electricity market. It is formulated the complex task of choosing effective mechanisms of purchase and sale on the electricity market on the basis of contracts for the implementation of markets "for the day ahead", as well as for the appointment of parameters and tariffs of the intraday market. The authors presented the models and results of calculations of optimum modes of trains' driving, which are calculated for various criteria of efficiency taking into account the cost of the consumed active and reactive electric energy. The technique of tariff formation for purchase of electricity on the balancing market was proposed.
\end{abstract}

\section{Introduction}

The report summarizes and discusses the results of research on the solution of a new and urgent task for railway transport - the formation of energy efficient and cost-effective methods for driving trains in the conditions of the development of the electric energy market in Ukraine. The hierarchical structures of complex tasks to ensure energy-optimal and cost-efficient electricity consumption processes of rail transportation are presented. A comparative analysis of their components, models and methods of implementation is conducted. Modern market forms and methods for providing traction power supply systems are considered, which require a revision of the methods for selecting the optimal train driving modes. An approach is proposed to solve the problem of reactive power compensation in power supply systems, which takes into account the charge for the consumption and generation of reactive power due to the formation of an appropriate train control criterion. There were given the optimal control modes in terms of consumption and cost management modes of trains on electrified sections, as well as rational control modes, taking into account the consumption of reactive energy, or by the criterion of the minimum cost of the consumed reactive power. For the calculation of driving modes, a model of stochastic optimal train motion control was used, as well as methods of fuzzy expert systems that provide rational modes of thrust based on simulation and processing control trips data.

\section{Relevance}

Railway Transport (RT) of Ukraine is one of the country's largest consumers of fuel and energy resources.
Reducing operating costs is an important direction in improving the competitiveness of railways. One of the most effective ways to save resources is the introduction of energy-optimal train schedules in the main directions of transportation $[1,2]$. In recent years, in connection with the formation and development in Ukraine of the Wholesale Electricity Market (WEM) [7], a new and relevant research area for railway has emerged - the formation of energy efficient and cost-effective train driving methods [3-5, 13]. In 1997 - 1999 railways of Ukraine were licensed for the right to transfer and energy supply on the basis of the regular tariff. The goal was to access cheap electricity on the Wholesale Market of Ukraine and reduce its own costs for its purchase. In 2002, the transition to WEM was first performed by the Pivdenno-Zahidna Railway, and in 2011, the last such transition was carried out by Odesskaya, Pivdenna and Lvivskaya railways.

The complexity of the task of optimal train control is determined by the completeness of taking into account the totality of factors characterizing the estimated section, model of the train, various conditions of the process of a train moving along a variable path profile, taking into account voltage changes at the current collector of a moving electric locomotive, arising forces, etc. $[1,3]$. Taking into account the conditions of the wholesale electricity market has significantly changed and expanded the factors of the tasks of managing train traction modes $[2,5]$. Differences in electricity tariffs for the periods of the day, the need to develop a package of mode maps (MM) and a corresponding adjustment of train control modes for the periods of the day, as well as taking into account differences in the cost of active and reactive energy, etc., have made relevant the requirements for more accurate calculation of electricity

Corresponding author: vkuznetsov@ikolej.pl 
consumption for train traction. For the first time, a significant impact of the conditions for the application of differentiated tariffs and tariffs on WEM for passenger train operation has been established in [2, 3]. When analyzing rational $\mathrm{MM}$ with variable electricity tariffs, a new important spatial-temporal relationship of the costenergy indicators with the tasks of organizing passenger and freight rail traffic in general is emerged.

Further development and improvement of methods for calculating the MM of freight trains in terms of the wholesale electricity market and with variable electricity tariffs was obtained in [3, 4]. Here, for the first time, were studied the optimal modes (in terms of the cost of the electricity consumed) of train operation under the conditions of stochastic tariffs typical of the wholesale electricity market. At the same time, an adaptive method was developed for calculating the train driving statistics based on a fuzzy production model[6]. The method allows to use the results of experimental trips for the formation of traction modes, and provides sufficient for practice the accuracy of controlling the movement of the train without specifying a detailed description of the parameters of mathematical models. In [4], the piecewise-linear approximation of the tariff for electricity in the WEM was constructed, containing four intervals and allowing one to calculate the optimal MM in terms of the cost of the electricity consumed. For the WEM conditions, the criteria for evaluating train schedules were improved, taking into account the different costs of active and reactive energy. At the same time, on the basis of experimental data, the dependence of the power factor was obtained, which makes it possible to calculate the adjusted modes of train traction taking into account the different cost of reactive and active electric power.

In 2005 was established a single tariff for electricity. Following it, the railways had to sell electricity to their customers at a single tariff. At the same time, the railways of Ukraine lost the opportunity to receive certain advantages from electricity purchases at a much lower price of WEM, and also completely lost the incentive to adjust their own consumption schedule and the opportunity to obtain a certain economic effect from it.

In 2017, the Verkhovna Rada of Ukraine adopted the Law of Ukraine "On the electricity market" [7]. The purpose of the new electricity market is to introduce competitive mechanisms for the functioning of the market, free choice of contractors and ensure the right of the consumer to freely choose the electricity supplier. The law provides for various mechanisms for the purchase and sale of electricity bilateral agreements, the market "for the day ahead" and the domestic market. Tariffs at which the electricity supplier sells electricity at an unregulated rate to its consumers are determined and established exclusively through negotiations, and are not regulated by the state. Since July 1, 2019, a new model of the balancing market of WEM has been functioning in accordance with the provisions of this law.

In connection with the functioning in Ukraine of the model of the balancing electricity market, the content of the tasks of the scope of the operations of the RT on the WEM has changed, as well as the significance and role of the above mathematical models used to organize rational transportation in the electrified sections. Namely, in the models of calculating the optimal MM of train operation in the conditions of the WEM, the train flow and electricity tariffs were considered as given. In the modern conditions of work of the RT on the balancing market, the parameters of train schedules and variations in the volumes and tariffs for electricity by day should be jointly justified and calculated by simulating transportation processes. The previously mentioned and other similar models should be used to select the most efficient mechanisms for buying and selling electrical energy, when concluding bilateral agreements, implementing the day-ahead markets, and also for setting parameters and tariffs for the intra-day market. The given article is devoted to the formation and justification of ways to solve these new tasks of the operation of the Ukrainian railways in the WEM.

\section{Setting targets for the calculation of energy efficient and cost-effective modes of driving trains in a balancing electricity market of Ukraine}

Let us consider the issues of a comparative analysis of the structure of complex tasks to ensure energyoptimal and cost-efficient power consumption of rail transport processes, as well as differences in mathematical models and implementation methods. The content of the main technological task of choosing energetically optimal train control modes (depending on the profile of the track, speed limits, a given time of movement on a certain section, taking into account the stochastic properties of voltages on current collector, monitoring the temperature of the traction engines, as well as other characteristics) means to calculate such values of control parameters, for example, positions of the ERS controller, which provide the best values of the vector of control quality indicators when performing and the system of requirements for the given characteristics of the train movement [1, 3]. Different components of the vector function of the target are possible $\left(\bar{F}\left(F_{k}\right)_{n}=\left(F_{1}, F_{2}, \ldots\right) ; F_{1}=Y\right.$ - traffic performance, $F_{3}=$ $C$ - cost of consumed electricity, $F_{4}=T$ - requirements for the time of fright delivery, $F_{5}=A$ - electricity consumption, etc.). They reflect various aspects of the operations of the RT and the requirements of the systems of various levels that organize and ensure the transportation process. The values of all components $\bar{F}\left(F_{k}\right)_{n}$ are essential in solving the problem of calculating the MM values $u\left(^{*}\right)$ - the parameters for controlling the movement of a train at a point of section $x$ at given time $t$ point: $u\left(x, t, U_{C}(E, \mu(t, s), \sigma(t, s))\right) \in u_{D}$, where $u_{D}-$ is the set of admissible controls. Further, the $U_{C}(*)$ voltage on the current collector of a moving electric locomotive at a point $x$, which has stochastic properties, is indicated, a $E$ the EMF of the traction substations; $(\mu(t, s), \sigma(t, s))$ respectively, the mathematical expectation and the 
standard deviation of the inter-train interval, which characterize the train flow associated with the movement of the calculated train on the section $s$. For brevity, "**" denotes sets of function arguments. Thus, already through the values $U_{C}\left(^{*}\right),(\mu(t, s), \sigma(t, s))$ as well as through some of the vector indicators $\bar{F}\left(F_{k}\right)_{n}$, the task of choosing the optimal train hauling modes at the level of the choice of $u\left(x, t, U_{C}(E, \mu(t, s), \sigma(t, s))\right)$ controls is included in the hierarchy of the railway systems. These systems are related to the implementation of the rail transport process as a whole. Figure 1 shows schematically the form of switching on a train, for which an energy-optimal (or at the minimum cost for the conditions of variable electricity tariffs as in $[2,4,5,10$ $11]$ is calculated for the section $s$, the multi-level structure of target indicators and other functional characteristics of the traffic .

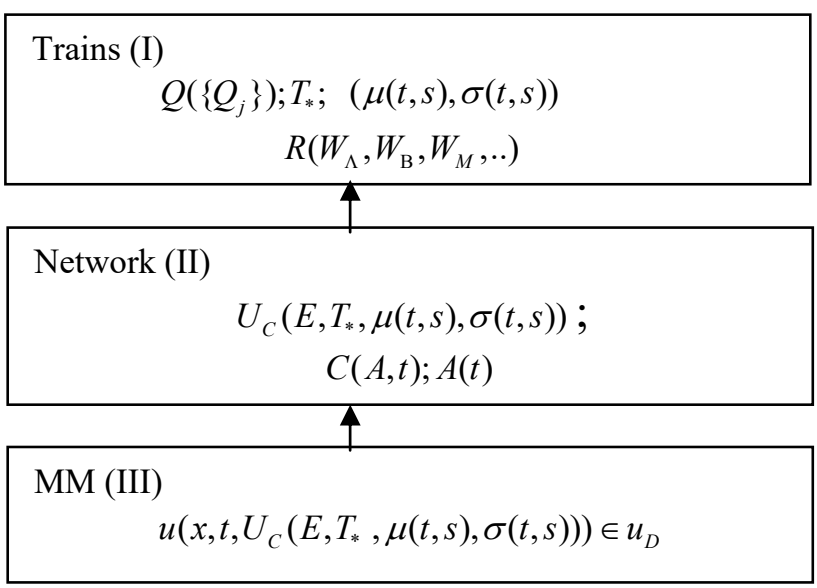

Fig. 1. The structure of the indicators for calculating the optimal MM

On fig. 1, the following characteristics are indicated: $Q\left(\left\{Q_{j}\right\}\right)$ - the volume of transportation by different categories of trains $Q_{j}, j \in\{g, n, e, v\}$, having different electricity consumption and driving modes, where $j=g$ it corresponds to freight trains, $j=n$ - passenger trains, $j=v$ - speed trains, $j=e$ - electric trains, etc .; $T_{*}-$ requirements for the time of movement; $(\mu(t, s), \sigma(t, s))$ - the parameters of the accompanying train; $R\left(W_{\Lambda}, W_{\mathrm{B}}, W_{M}, ..\right)$ - vector of transportation resources, where $W_{\Lambda}$ - locomotives, $W_{B}-$ wagons, $W_{M}$ - financial resources, etc.; $A(t)$ - indicators of electricity consumption by periods of the day $t ; C(A, t)$ - the cost of electrical energy; the remaining characteristics are defined above.

The articles [2, 5] discussed an approach to solve a multi-level complex problem of MM optimizing. 1, from the standpoint of stochastic programming. At the same time, fig. 1, three levels of the model were distinguished: -1) train flows, - 2) electric traction network, - 3) train operation modes. Given the parameters of the train flow, the characteristics of the transportation processes for levels (II) - (III) are: electricity consumption for train traction, cost of electricity consumed for traction, losses in the traction network, average voltage level at the current collector, travel time on section, engine temperature, etc.

The qualitative difference and the complexity of the tasks of simulating of RT on the balancing electricity market, from the problems of choosing MM that are optimal in terms of cost or energy-efficient, which were previously used in railway transport of Ukraine, consists in changes in the models' structure of the systems fig. 1. In the conditions of a balancing WEM, the levels of model (I) and (II) should be swapped, or be realized together. At the same time, the planning of train flows should be carried out taking into account the tariff for electricity established on the basis of bilateral agreements, day-ahead markets, and the assignment of parameters for the intra-day market. Previously developed models of railway transportation processes should be used to ensure the completeness and accuracy of calculations of the optimal consumption and cost of electrical energy, as well as to obtain reliable MM for trains.

In this paper, further in the calculations, one of the known and complete models of the equations of train motion was used. It takes into account the parameters of the train length, temperature changes of the traction engine and other factors $[1,3]$. This model turned out to be sufficient for the development of cost-effective MM for driving passenger and freight trains. A moving train seemed to be a flexible thread of length $L_{n}$ with constant mass $p_{n}(z), \quad 0 \leq z \leq L_{n}$. The dynamics of train motion is described by a system of differential equations (1) with initial conditions $(2)[1,2]$

$$
\begin{gathered}
\frac{d\left(v^{2}\right)}{d x}=\frac{2 \zeta}{(q+Q)(1+\gamma)}\left[F_{e}\left(x_{e}\right)-W\left(x_{w}\right)-B_{T}\left(x_{B}\right)\right] ; \\
\frac{d \tau}{d x}=\frac{\tau_{*}\left(I_{D}\left(v\left(u(x, t), U_{C}(x, t, \theta)\right)\right)-\tau(x, t)\right)}{v(x, t) T_{D}\left(I_{D}\left(v\left(u(x, t), U_{C}(x, t, \theta)\right)\right)\right)} ; \\
x(0)=x_{0} ; v(0)=v_{0} ; \tau(0)=\tau_{0},
\end{gathered}
$$

where: $x, t-$ coordinates of the way and time; $-u(x, t)-$ control (position number of the controller); $-v-$ the speed of the center of mass of the train; - masses $q, Q_{-}$ of locomotive and train; - $F_{e}-$ the power of the locomotive; - $U_{C}\left(^{*}\right)$ - voltage in contact network; $W(*)$ - resistance to the forward movement of the train; - $B_{T}$ braking force acting on the train; - $\gamma$ - the coefficient of inertia of the rotating masses; $\zeta=g / 1000, g-$ acceleration of gravity; $-\tau-$ heating temperature of the traction engines; - $\tau_{*}=\tau \infty, T_{D}, I_{D}-$ thermal characteristics and currents of the traction engines; $\quad-\quad x_{e}=\left(v, u, U_{C}\right) ; \quad x_{w}=(x, v, u)$; $x_{B}=\left(v, k^{\prime}(t), u, U_{C}\right),-k^{\prime}(t)-$ total force of pressing of brake blocks; - $\theta$ - random and uncertain factors of the task. 
In (1) - (2), the time coordinate is $t$ introduced to enable the choice of controls depending on the period of the day. The motion model also takes into account the random nature of the alternating voltage on the current collector, which occurs when the locomotive moves $U_{C}(*)$.

The resistance to the forward movement of the train in (1) - (a) took into account: the resistance to movement of the train from the longitudinal profile of the track, $i$ the slope value; resistance to movement from curves in terms of the path; $i_{\mathrm{r}}$ - resistivity from curves; area of permissible phase trajectories (starting and ending coordinates of the track; $\tau_{\text {доп }}$ - maximum permissible engine overheating temperature; $v^{\max }(x)$ - permissible train speed). The restrictions imposed on controls $u(x)$ in accordance with the rules of technical operation included: $\tilde{U}$ - the scope of admissible controls; $I_{\text {д }}^{\max }$ maximum permissible current of engine; $q_{0}$ - vehicle axle load; - the $\psi_{\mathrm{K}}$ coefficient of adhesion of the wheel with the rail; $K^{\prime \prime}$ - force of pressing of wheel pair brake block; $\varphi_{\mathrm{K}}$ - the coefficient of friction of the brake block on the wheel. The train moving time on the section was represented by an isoperimetric constraint.

In the tasks of selecting energy-optimal train traction modes, the criterion for assessing the quality of the control law on the section $u(x)$ was the minimum of the functional representing electricity consumption.

$$
A[u]=\int_{x_{\mathrm{H}}}^{x_{\mathrm{K}}} \frac{U_{\mathrm{c}} I_{\mathrm{da}}(v, u) d x}{v(x, u)},
$$

where is $I_{\mathrm{da}}(v, u)$ the active current of the locomotive.

The task of choosing the optimal MM is following: it is necessary to calculate such a control law $u^{*}(x) \in \tilde{U}$ so that the corresponding solution of the system of equations (1) - (2) belongs to the admissible region, and the objective functional optimality (3) takes the minimum value.

The calculations of the optimal MM also took into account the alternating voltage at the current collector of a moving electric locomotive. It was estimated on the basis of the accompanying train traffic (ATT) model, as well as estimates of the voltage drop from the own current of the locomotive [2]. To do this in [3] were developed the models for the statistical estimation of the parameters of ATT for several types of trains and models for estimating the parameters of ATT based on the theory of fuzzy sets [6].

\section{Optimal modes of conducting freight trains, taking into account the cost of active and reactive power}

Along with the active power of the electricity supplier, the reactive power is also taken into account, which is payable at the established tariffs. The main part of the power in RT is consumed by locomotive electric engines, their asynchronous electric motors are consumers of reactive power. In the absence of compensating devices in the networks, the reactive current is supplied to the engines from the power supply networks, and is payable. In Ukraine, the fee for the consumption of reactive power is determined according to:

$$
\Pi=\Pi 1+\Pi 2-\Pi 3
$$

where $\Pi 1$ - the main fee for the consumption and generation of reactive electricity; П 2 - surcharge (for $>$ $\operatorname{tg} \phi 0.25)$ for insufficient equipment of the consumer's electrical network; $\Pi 3$ - payment discount in the billing period. The amount $\Pi 2$ of the allowance has a nonlinear dependence $\operatorname{tg} \varphi$, and $\operatorname{tg} \phi>0,6$ can take values comparable to the main payment $\Pi 1$ for the consumption and generation of reactive electricity [4].

Reducing the value $\operatorname{tg} \phi$ is a rather difficult task that can be solved by introducing rational MM using the criterion of minimizing the consumption of reactive energy or reducing the charge for the consumed reactive energy. In $[4,5]$ was used a functional to estimate the control indicator at the $\operatorname{section} u(x)$, which took into account the costs of active and reactive energy of the form:

$$
\begin{aligned}
& A[u]=\int_{x_{u}}^{x_{\kappa}} \frac{U_{c} I_{d a}(v, u) \cdot c(t) d x}{v(x, u)}+ \\
& \int_{x_{u}}^{x_{\kappa}} \frac{U_{c} I_{d a}(v, u) \cdot \sin \phi \cdot\left(I_{d a}(*)\right) \cdot D \cdot c(t) d x}{v(x, u)}+\Pi 2
\end{aligned}
$$

where $I_{\mathrm{da}}(v, u)$ - the active current of the locomotive, the first member reflects the cost of consumption of only active energy, and the second - the cost of the reactive energy, $D$ - coefficient of influence of the reactive power flow. $\Pi 2$ - surcharge (5), $c(t)$ - the price coefficient of the tariff taking into account the time of day $t$;

$$
\Pi 2=\Pi 1 * C_{\mathrm{bas}} *\left(K_{f}-1\right)
$$

In (6) $\Pi 1$ is the main cost for the consumed and generated reactive energy, $C_{\text {баз }}=1$ the standard value of the coefficient of capital investments; $K_{\phi}$ - the estimated coefficient for the value $\operatorname{tg} \varphi$ of the consumer. For AC RT $\Pi 2$ there are no surcharges.

To construct the characteristic $\cos \phi$ (5) were used data from experimental trips on the locomotive VL-80t [4] and Skoda [9]. The approximating dependencies of the values on $\cos \phi\left(I_{\mathrm{da}}\right)$ the total current of the locomotive had the form:

$$
f(x)=\frac{A}{B-e^{-C x}}
$$

Fig. 2 presents the results of tests and approximating their dependence. 


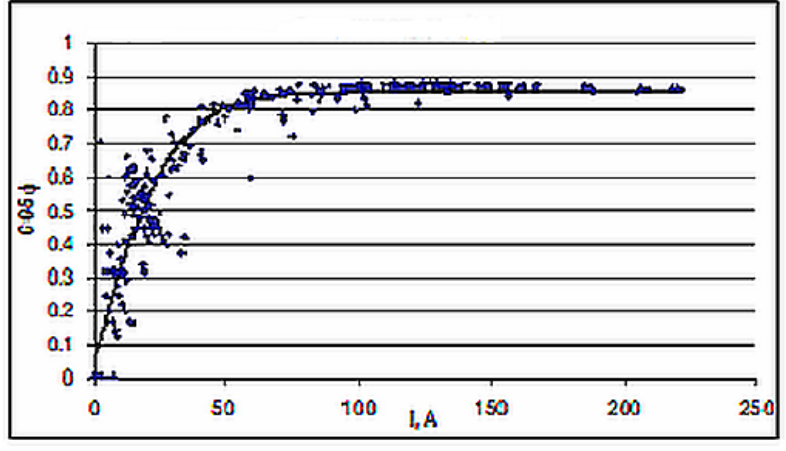

Fig. 2. Function approximation $\cos \phi\left(I_{\mathrm{da}}\right)$

The optimal modes of train control taking into account the values of active and reactive power, are shown at fig. 3 - fig. 5. Here for the same travel time over one track section are given the results of calculations of the train route section speeds, taking into account the flow rate and payment for the active and reactive power components. Horizontal lines limit speeds on track sections. The figures show these parameters - the time of movement on the section, electric energy consumption, as well as the number of time zones, if there were more than 1.

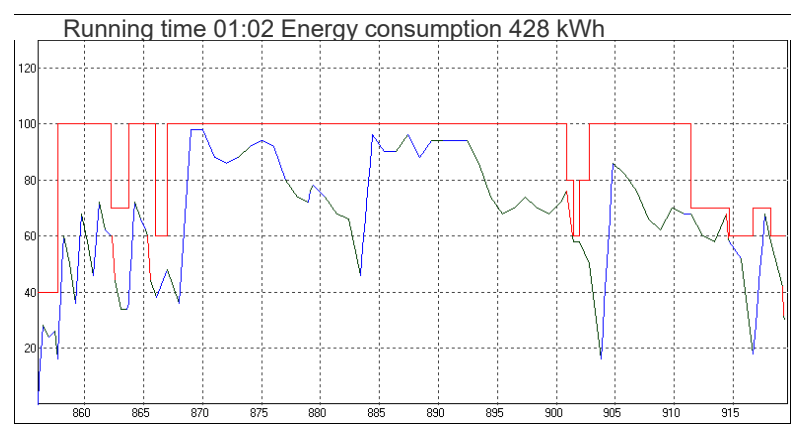

Fig. 3. Optimization of traction modes on the basis of total energy consumption

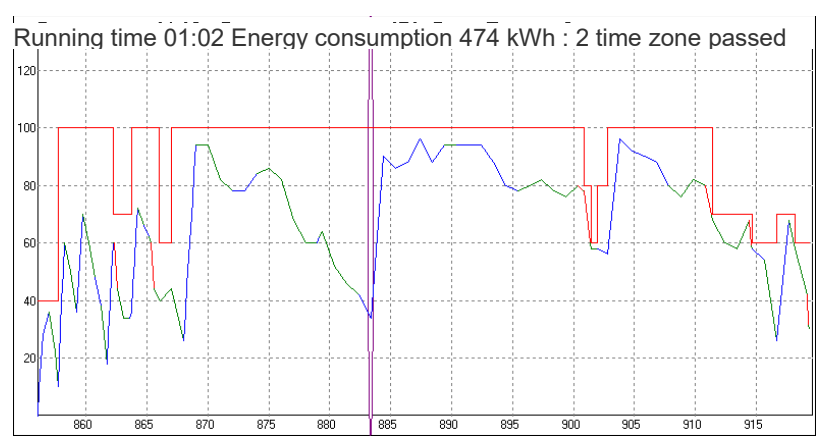

Fig. 4. Optimization of traction modes with regard to reactive energy cost

For the first case on fig. 3 the power consumption was minimal (the cost of energy is not taking into account). For the case on fig. 4 electricity consumption is bigger, but here more electric energy was used in the zone with a lower hourly rate to reduce the cost. For modes on fig. 5 the cost of energy is calculated more accurately taking into account the cost of reactive energy. We note the qualitative difference in the nature of train' control under various optimization criteria. In general, the calculations showed that the criteria developed and given by us, as well as models for optimizing train traction modes with the required accuracy provide both electricity metering and the expected estimate of its value in the framework of the new electricity market of Ukraine.

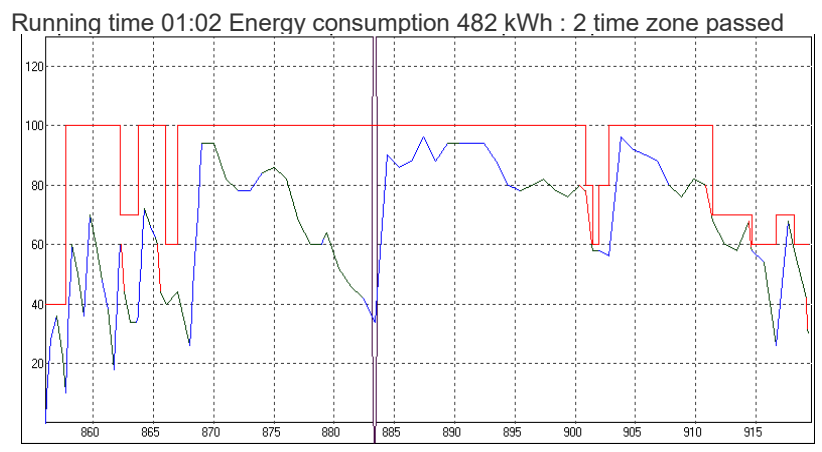

Fig. 5. Optimization of traction modes on the basis of the cost of full energy consumption

\section{Methods of research and the formation of tariff models for the purchase of electricity on a balancing WEM}

Previously, we pointed out a new task for simulating the power supply processes associated with the operation of RT on the balancing market - the selection and designation of rational parameters of the intra-day market. A reasonable choice of intraday tariffs of the WEM will then make it possible $\mathrm{n}$ for RT to plan the purchase of electricity and the transportation process in an advantageous way, fig. 1 . The assignment of rational intraday tariffs of the WEM can be represented as a choice of relative hourly coefficients for a given base, single, tariff. As established in $[2,4,8]$, variable tariffs require the development and implementation of $\mathrm{MM}$ packages used during different periods of the day. Since the change in intraday tariffs of the WEM cannot occur every hour, the problem of constructing an approximation of the tariff for electricity less than 24 in the number of relative price coefficients must be solved. To solve it can be used the methodology and procedures by which the four-zone approximation of the price of electricity in the WEM of Ukraine was previously obtained, presented in [4]. In the conditions of the new WEM of Ukraine, this technique should be part of a more general model for automating the choice for RT the intraday tariffs.

In order to clarify the content of the new tariff formation method, we will schematically show the stages of obtaining four zone approximation. On the basis of observational data was obtained an area of random estimates of the cost of electricity in the WEM over the periods of the day, were determined the averaged price coefficients. Further, calculations were made of the costeffective MM when departing trains of a given weight every hour. Then, an approximation of the WEM hourly tariff was introduced using three or four zone tariffs, when the tariffs were set by relative coefficients. In table 
1 are shown the calculated errors for approximate estimates of the cost of electricity consumption obtained using three or four zone tariffs for freight trains of different weights. On fig. 6 are presented comparative estimates graphically. The figure shows various models of variable tariffs for electricity: - DT, differentiated tariffs; - OPE, wholesale market rates; - OPE3, OPE4 tariffs for three and four zone approximation of cost in the WEM.

Table 1. Comparative analysis of the accuracy of WEM tariff approximation

\begin{tabular}{|l|l|l|l|l|l|}
\hline $\begin{array}{l}\text { Ratio } \\
\text { tariffs }\end{array}$ & $\begin{array}{l}\text { Train1 } \\
3000 \\
\text { t. }\end{array}$ & $\begin{array}{l}\text { Train2 } \\
4050 \\
\text { t. }\end{array}$ & $\begin{array}{l}\text { Train3 } \\
5025 \\
\text { t. }\end{array}$ & $\begin{array}{l}\text { Train4 } \\
6000 \\
\text { t. }\end{array}$ & $\begin{array}{l}\text { percentage } \\
\text { of error }\end{array}$ \\
\hline $\begin{array}{l}\text { OPE/ } \\
\text { OPE4 }\end{array}$ & $-0,3 \%$ & $-1,5 \%$ & $-1,5 \%$ & $-1,9 \%$ & $-1,3 \%$ \\
\hline $\begin{array}{l}\text { OPE/ } \\
\text { OPE3 }\end{array}$ & $-3,2 \%$ & $-2,5 \%$ & $-1,6 \%$ & $-2,9 \%$ & $-2,5 \%$ \\
\hline
\end{tabular}

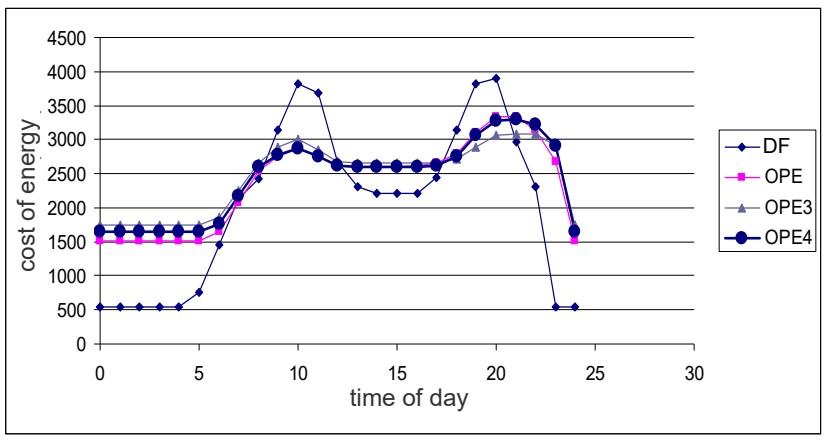

Fig. 6. Models of comparative estimates of the electric energy tariff

Thus, the four-zone model of approximation of tariffs made it possible with sufficient accuracy to replace the stochastic prices of the Ukrainian wholesale electricity market. An important feature of this method is that a rational model of approximation of tariff coefficients was chosen based on the analysis of the specified areas of their values by periods of the day, regardless of the train schedule. This circumstance serves as the basis for the decomposition of the tasks of modelling the power supply of the RT in the conditions of the balancing market of WEM. At the first stage of simulating of the electricity procurement, one should select three or four zone tariff models, and then set tariff coefficients using a simulation method and form a train schedule on the given section. Thus, the structure of the procurement model is as follows: Network - Train - MM.

The task of selecting zone tariff coefficients can be represented as an optimization model as follows: it is required to calculate four values of zone tariffs and build a timetable for a given set of trains of different categories (assign departure and arrival times taking into account the established system of restrictions) in order to minimize the total cost of electrical energy of the WME consumed for train traction, based on the optimal MM traffic with variable tariffs. The mathematical models and methods for selecting the optimal traction modes indicated earlier in the article should be used in solving this complex problem.

\section{Conclusions}

The problems of reducing operating costs through the introduction of energy and optimal at the cost of train schedules are among the highest priority for the railway transport of Ukraine. The introduction of the balancing electricity market in Ukraine in 2019 opens up new opportunities for organizing efficient transportation on the electrified sections of railways.

The article reviewed some new possibilities for using mathematical models for optimizing train driving modes according to the criteria for the minimum cost of consumed active and reactive electric energy. At the same time, a complex task was formulated for choosing the most efficient mechanisms for buying and selling electric energy in the wholesale electricity market of Ukraine, which are used in concluding bilateral agreements on the day-ahead markets, as well as setting parameters and tariffs for the intraday market.

The paper shows a significant difference in the optimal driving conditions of trains, which are calculated for different performance criteria, taking into account the charges for the consumed active and reactive energy. It has been established that the models used to optimize train traction modes are sufficient for WEM conditions. The method of forming zone tariffs presented in the article can be used for models in order to purchase of electricity in the balancing market.

\section{References}

1. E. P. Blokhin, A. N. Pshinko, G. V. Evdomaha, V. V. Skalozub, V.B. Zemlyanov Selection of energetically optimal train operation regimes Railway Transport of Ukraine, No. 6, P. $19-22$ (2001). [in Russian]

2. E. P. Blokhin, V. V. Kornienko, V. V. Skalozub Resource-saving methods of train control with variable tariffs for electricity. Sb. "Electrification and scientific and technical progress in railway transport". Russia, Saint-Petersburg, P. 112-118 (2004). [in Russian]

3. G. V. Evdomomaha, V. V. Skalozub, K. G. Zheleznov, A. P. Ivanov. Modes of conducting passenger trains, taking into account the random voltage in the traction network and differentiated tariffs for electricity. Bulletin of Dnipropetrovsk National University of Ralway Transport, Iss. 3, P. 65 -73 (2004). [in Russian]

4. A. P. Ivanov. Study of train operation modes taking into account the cost of active and reactive energy. Bulletin of Dnipropetrovsk National University of Transport and Transport, Iss. 21, P. 239-242 (2008). [in Russian]

5. V. V. Skalozub, V. G. Kuznetsov, D. A. Bosy, A. P. Ivanov. Optimization of train operation modes on the basis of the criterion of minimum cost of consumed and reactive power. Information-Control Systems for Railway Transport, 4 (78), P. 111 - 115 (2008). [in Russian] 
6. V. V. Skalozub, A. P. Ivanov. Selection of train control modes based on fuzzy production model. Bulletin of the Belarusian State University of Transport, Belarus, Science and Transport, 1-2, P. 41 - 46. (2007) [in Russian]

7. Law of Ukraine «On the electricity market». Access mode https://zakon.rada.gov.ua/laws/show/2019-19 (access date 09.07.2019). - Title from the screen.

8. V. G. Sychenko,V. G. Kuznetsov, D. O. Bosyi, O. I. Sablin. Power engineering of traction networks. Dnipro: Publ. PF "Standard-Service", 210 p. (2017). [in Ukrainian]

9. P. Hubskyi, V. Kuznetsov, A. Drubetskyi, A. Afanasov, M. Pulin. Studying of the power modes in the traction line for ensuring the high-speed traffic. Technology audit and production reserves. Vol 5, no 1(43). Industrial and technology systems. P. 42-51 (2018).
10. S. V. Arpul, G. K. Getman, A. I. Kyiko, Yu. V. Mykhailenko The choice of rational parameters of the nominal mode of passenger electric locomotivesю. Dnepropetrovsk: Makovetskyi, (2012) - 188 c. [in Russian]

11. A. M. Afanasov, A. Ye. Drubetskiy, S. V. Arpul, A. P. Khvorostyankina Energy efficiency determination of loading-back system of electric traction machines. Science and transport progress. Bulletin of Dnipropetrovsk National University of Transport and Transport - Iss. 2(50). - P. 67-73 (2014) [in Russian]

12. P. Daszkiewicz, M. Andrzejewski, MATEC Web of Conferences, Preliminary analyzes in terms of the possibility of reducing energy consumption by the SM42 locomotive used in track works Volume: 118, DOI: 10.1051/matecconf/201711800014, (2017). 